\title{
Adaptive split course radiotherapy for skin cancers decreases toxicity and improves compliance
}

\begin{abstract}
The aim of this study was to investigate if definitive Adaptive Split Course Radiotherapy (ASCRT) of significant skin cancers could be done safely and successfully in select patients for whom a continuous course of fractionated treatment may have been too arduous. Two patients with three skin cancers were treated with ASCRT. The first case involved a large Basal Cell Carcinoma (BCC) on 91year-old woman's right temple. The second case involved two cutaneous Squamous Cell Carcinomas (SCC), a large lesion on the left anterior shin and a smaller on the right of a 92year-old woman with oedematous legs. Treatment volume reductions between phase one and two were on average $56 \%$, both completed the prescribed radiotherapy (RT) course, both had minimal acute reactions, and there was complete responses in all three primary sites at 6 weeks post RT. To our knowledge, this is the first report on the curative use of ASCRT for skin cancer. The findings of this study indicate that ASCRT is an effective modality for the treatment of skin cancers in select patients.
\end{abstract}

Volume 2 Issue I - 2017

\author{
Georgia R Carney, Karly Rose McLaren, Zoe \\ Moutrie, Gerald B Fogarty \\ Department of Radiation Oncology, Australia
}

Correspondence: Gerald B Fogarty, Department of Radiation Oncology, Genesis Cancer Care, Mater Hospital, P.O. Box 1003, Crow's Nest, NSW 2065, Australia, Email gerald.fogarty@cancer.com.au

Received: October 01, 2016 | Published: January 26, 2017

Keywords: skin neoplasms, radiotherapy, squamous cell carcinoma, basal cell carcinoma, skin cancer, patient

Abbreviations: ASCRT, adaptive split course radiotherapy; RT, radiotherapy; BCC, basal cell carcinoma; SCC, squamous cell carcinomas; SCRT, split course radiation therapy

\section{Introduction}

The incidence of skin cancer is increasing around the world, with Australia having the highest rates. ${ }^{1}$ As skin cancer incidence increases with age ${ }^{2}$ and the population of Australia is aging, there is great need for effective therapies. However, older patients can have significant co-morbidities that make definitive treatment challenging. There is no gold standard for skin cancer treatment based on level one evidence. ${ }^{3}$

Definitive radiotherapy (RT) is an option for these patients but they can also suffer from decreased mobility, making attending a fully fractionated course problematic. We hypothesized that, as these cancers are visible on the skin, this facilitates careful monitoring. Definitive radiotherapy with Adaptive Split Course Radiotherapy (ASCRT), with RT given in two phases separated by weeks, could be done safely in select patients for whom a continuous course of treatment may have been too arduous on them and on family members responsible for providing transport. We hypothesized that the split course may also lead to a significant reduction in the treatment volume for the second phase, so that late toxicity would be kept to a minimum.

\section{Materials and methods}

We treated two patients with three skin cancers with ASCRT. Each patient's treatment was prepared using 3D treatment planning system Eclipse Version 11 (Varian Medical Systems, Palo Alto, USA) with an electron Monte Carlo algorithm (eMC). ${ }^{4}$ The treatment was delivered using a Truebeam linear accelerator (Varian Medical Systems, Palo Alto, USA). The delivered dose was verified in vivo using the technique described by Moylan et al. ${ }^{5}$

\section{Case I}

The first case involved ASCRT of a large Basal Cell Carcinoma
(BCC) on 91year-old woman's right temple (Figure 1A). The patient was irradiated with 20 Gray (Gy) in five fractions at three fractions per week. RT was delivered to a 7 X $5 \mathrm{~cm}$ field using 6 Mega electron volt $(\mathrm{MeV})$ with five millimeters $(\mathrm{mm})$ of bolus over all the field. The RT was prescribed to the $90 \%$ isodose line. Four week afterwards there had been significant shrinkage (Figure 1B). In phase two, 20Gy in 5 fractions was delivered at three per week to a reduced circular field measuring $4 \mathrm{~cm}$ in diameter. Six $\mathrm{MeV}$ was again prescribed to the $80 \%$ isodose line with $5 \mathrm{~mm}$ of bolus to the newly reduced field.

Total dose was 40Gy given over 6 weeks with a gap of four weeks. Using the $85 \%$ isodose line as a measure of the treatment volume, this reduced from $19.58 \mathrm{~cm}^{3}$ at the beginning of the first course to $7.24 \mathrm{~cm}^{3}$ at the beginning of the second a volume reduction of $63 \%$. Eight weeks following treatment she had a complete response (Figure 1C).

\section{Case 2}

The second case involved ASCRT of two Squamous Cell Carcinomas (SCC) of a 92year-old woman with oedematous legs causing poor mobility requiring walking with a frame (Figure $2 \mathrm{~A}$ ). We treated the smaller lesion on the right anterior shin measuring $3.6 \mathrm{~cm}$ in diameter and the larger lesion on the left anterior shin measuring $5.2 \mathrm{~cm}$ in diameter.

The patient was treated with $25 \mathrm{~Gy}$ in 10 Fractions over two weeks to both lesions. The lesions were irradiated daily via an election beam technique, with the right small lesion receiving $6 \mathrm{MeV}$ and the left larger lesion $9 \mathrm{MeV}$ to account for its greater depth. Four weeks after the first course she represented for the second phase. Both lesions had significantly reduced (Figure $2 \mathrm{~B}$ ). Using the $80 \%$ isodose line as a measure of the treatment volume, the right leg SCC reduced from $24.27 \mathrm{~cm}^{3}$ at the beginning of the first course to $8.12 \mathrm{~cm}^{3}$ at the beginning of the second with a volume reduction of $66.5 \%$. The larger SCC on the left leg reduced from $75.35 \mathrm{~cm}^{3}$ to $45.16 \mathrm{~cm}^{3}$ with a volume reduction of $41.1 \%$. A further dose of $25 \mathrm{~Gy}$ given over 2 weeks using $6 \mathrm{MeV}$. Eight weeks following treatment she had a complete response (Figure 2C). 

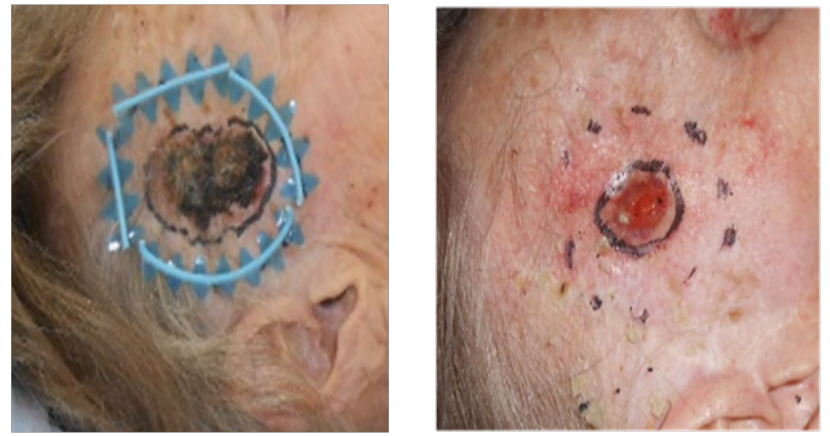

Figure IA Large BCC on temple at baseline. Figure IB Four weeks after phase I.

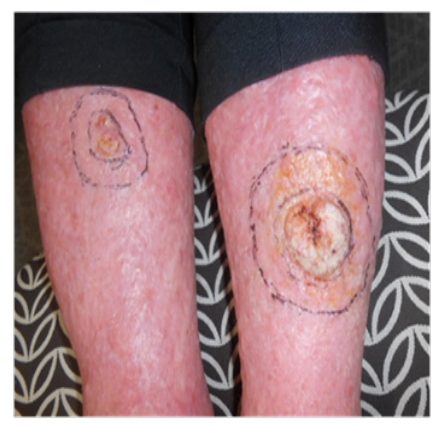

Figure 2A Bilateral SCC on shins at baseline.

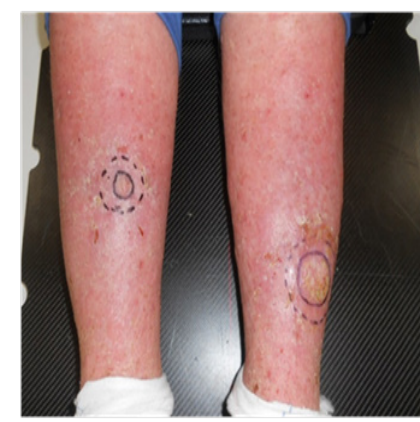

Figure 2B Four weeks after phase I.

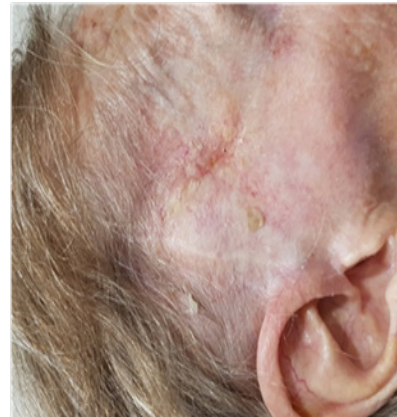

Figure IC Six weeks after phase 2.

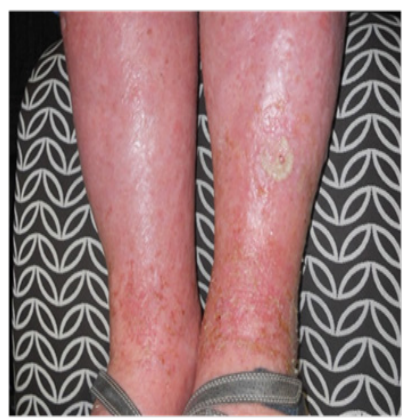

Figure 2C Six weeks after phase 2.

\section{Results and discussion}

Both patients had treatment volume reductions between phase one and two, averaging 56\%. Both completed the prescribed RT course. Both had minimal acute reactions, and there were complete responses in all three primary sites at 6 weeks post RT. The results are tabulated in table one. Our two cases involving three locally advanced skin cancers in two elderly patients with multiple comorbidities and challenged mobility were successfully treated with definitive megavoltage radiotherapy using an adaptive split course technique. A large facial BCC decreased significantly in size during the four week split allowing for a volume reduction in the second part of the course. The second case with two SCCs of the anterior shins had significant shrinkage at four weeks after the first phase. There were no RTOG grade $2^{6}$ or greater acute skin reactions. The full course of RT was delivered. There was average shrinkage of $56 \%$ between the first and second planning visits. There was a complete response in all three lesions at 6 weeks following completion of all treatment. Fractionation was kept to a minimum.

These are the first reported cases of adaptive split course radiotherapy (ASCRT) for the definitive radical treatment of skin

Table I Changes to the skin lesions during adaptive split course radiotherapy

\begin{tabular}{|c|c|c|c|c|c|c|}
\hline $\begin{array}{l}\text { Patient/body Site/ } \\
\text { histopathology }\end{array}$ & $\begin{array}{l}\text { RT volume at } 80 \% \\
\text { line at start of } \\
\text { phase I }\end{array}$ & $\begin{array}{l}\text { Phase I total } \\
\text { gray/fractions }\end{array}$ & $\begin{array}{l}\text { RT volume at } \\
80 \% \text { line } 4 \text { weeks } \\
\text { post phase I }\end{array}$ & $\begin{array}{l}\text { Reduction (\%) } \\
\text { phase I to } \\
\text { phase } 2 \text { (Ave } \\
56 \% \text { ) }\end{array}$ & $\begin{array}{l}\text { Phase } 2 \text { total } \\
\text { gray/fractions }\end{array}$ & $\begin{array}{l}\text { Result } \\
\text { 6weeks } \\
\text { after RT }\end{array}$ \\
\hline I/Temple/BCC & $19.58 \mathrm{~cm}^{3}$ & $20 / 5$ & $7.24 \mathrm{~cm}^{3}$ & 63 & $20 / 5$ & $\mathrm{CR}$ \\
\hline 2/ Right leg/SCC & $24.27 \mathrm{~cm}^{3}$ & $25 / 10$ & $8.12 \mathrm{~cm}^{3}$ & 66 & $25 / 10$ & $C R$ \\
\hline 2/ Left Leg/SCC & $75.35 \mathrm{~cm}^{3}$ & $25 / 10 *$ & $45.16 \mathrm{~cm}^{3}$ & 40 & $25 / 10$ & $\mathrm{CR}$ \\
\hline
\end{tabular}

$\mathrm{RT}$, radiotherapy; $\mathrm{CR}$, complete response; Ave, average

$*$ This course used $9 \mathrm{MeV}$ all others used $6 \mathrm{MeV}$

cancers. This technique is truly adaptive as defined in the radiotherapy literature. Adaptive radiotherapy occurs when treatment volumes are finessed during a course of radiotherapy to take into account the change in tumor volume during the therapy. Changing the volume increases dose conformality and leads to a better therapeutic ratio. ${ }^{7}$

This technique is also a split course. Split Course Radiation Therapy (SCRT) refers to a regime of RT that is broken into at least two phases, with each phase being separated by a rest interval, usually four weeks, to allow for the healing of acute toxicities such as mucositis and desquamation. This method has been used in the treatment of head, neck $^{8}$ and anal cancers ${ }^{9}$ but abandoned due to decreased local control thought to be due to accelerated repopulation. ${ }^{10}$ However, SCRT could be coming back into vogue in scenarios similar to ours. ${ }^{11}$

The findings of this study indicate that ASCRT is an effective modality for the treatment of skin cancers in select patients. There are a number of limitations in this study that need to be acknowledged. Firstly, only two patients were involved. The histologies were also different. Despite this, the fact that both patients had a complete response to the treatment is of merit, and suggests that ASCRT is a suitable option for patients who may find longer RT courses, or alternative treatments such as surgical excision, to be challenging. 


\section{Conclusion}

Two patients with three skin cancers were treated with ASCRT. Both had significant co-morbidities and mobility issues that made surgery and continuous RT courses too arduous. The first case involved a large Basal Cell Carcinoma (BCC) on 91year-old woman's right temple. The second case involved two cutaneous Squamous Cell Carcinomas (SCC), a large lesion on the left anterior shin and a smaller on the right of a 92year-old woman with oedematous legs. Treatment volume reductions between phase one and two were on average $56 \%$, both completed the prescribed radiotherapy (RT) course, both had minimal acute reactions, and there was complete responses in all three primary sites at 6 weeks post RT. To our knowledge, this is one of the first report on the curative use of ASCRT for skin cancer. The findings of this study indicate that ASCRT is an effective modality for the treatment of skin cancers in select patients.

\section{Acknowledgements}

The authors of this paper would like to thank Diana $\mathrm{Ng}$ and the staff of the Department of Radiation Oncology at the Mater Hospital, Sydney for their help throughout this study. In particular, Kerryn Miller for her assistance in obtaining patient photographs for providing their support and care for both patients involved in this study. This study was also presented as poster 2016 Innovations in Cancer Treatment and Care Conference on Friday 16 September 2016 at the Australian Technology Park (ATP), Sydney.

\section{Conflict of interest}

Author declares that there is no conflict of interest.

\section{References}

1. Staples MP, Elwood M, Burton RC, et al. Non-melanoma skin cancer in Australia: the 2002 national survey and trends since 1985. Med J Aust. 2006;184(1):6-10.
2. Non-melanoma skin cancer: general practice consultations, hospitalization and mortality. Australian Government. Australia; 2008.

3. Hextall BF, Bee LJ, Somchand N, et al. Interventions for preventing non-melanoma skin cancers in high-risk groups. Cochrane Database Syst Rev. 2007;17(4):CD005414.

4. Hu YA, Song H, Chen Z, et al. Evaluation of an electron Monte Carlo dose calculation algorithm for electron beam. J Appl Clin Med Phys. 2008;9(3):2720.

5. Moylan R, Aland T, Kairn T. Dosimetric accuracy of Gafchromic EBT2 and EBT3 film for in vivo dosimetry. Australas Phys Eng Sci Med. 2013;36(3):331-337.

6. https://www.rtog.org/ResearchAssociates/AdverseEventReporting/CooperativeGroupCommonToxicityCriteria.aspx

7. Capelle L, Mackenzie M, Field C, et al. Adaptive radiotherapy using helical tomotherapy for head and neck cancer in definitive and postoperative settings: initial results. Clin Oncol (R Coll Radiol). 2012;24(3):208-215.

8. Mieszczyk L, Maciejewski B, Tukiendorf A, et al. Split-course accelerated hyperfractionated irradiation (CHA-CHA) as a sole treatment for advanced head and neck cancer patients-final results of a randomized clinical trial. Br J Radiol. 2014;87(1041):20140212.

9. Weber DC, Kurtz JM, Allal AS. The impact of gap duration on local control in anal canal carcinoma treated by split-course radiotherapy and concomitant chemotherapy. Int $J$ Radiat Oncol Biol Phys. 2001;50(3):675-680.

10. Bese NS, Hendry J, Jeremic B. Effects of prolongation of overall treatment time due to unplanned interruptions during radiotherapy of different tumor sites and practical methods for compensation. Int $J$ Radiat Oncol Biol Phys. 2007;68(3):654-661.

11. Bledsoe TJ, Noble AR, Reddy CA, et al. Split-Course Accelerated Hypofractionated Radiotherapy (SCAHRT): A Safe and Effective Option for Head and Neck Cancer in the Elderly or Infirm. Anticancer Res. 2016;36(3):933-939. 